\title{
Application of Fuzzy Analytical Hierarchy Process based on Geometric Mean Method to Prioritize Social Capital Network Indicators
}

\author{
Vy Dang Bich Huynh ${ }^{1}$ \\ Department of Learning Material \\ Ho Chi Minh City Open University (HCMCOU) \\ Ho Chi Minh City, Vietnam \\ Phuc Van Nguyen ${ }^{2}$ \\ Ho Chi Minh City Open University (HCMCOU) \\ Ministry of Education and Training (Hanoi) \\ Vietnam
}

\author{
Quyen Le Hoang Thuy To Nguyen ${ }^{3}$ \\ Office of Cooperation and Research Management \\ Ho Chi Minh City Open University (HCMCOU) \\ Ho Chi Minh City, Vietnam \\ Phong Thanh Nguyen ${ }^{4}$ \\ Department of Project Management \\ Ho Chi Minh City Open University (HCMCOU) \\ Ho Chi Minh City, Vietnam
}

\begin{abstract}
Vietnam is striving to develop dynamically and overcome many human resource challenges. As the economy expands, the demand for jobs and human resource development has become increasingly critical. The pressures from reform and international integration are forcing many changes. New graduates must provide proof of their academic capabilities, while also actively developing their social capital to support their job search process. In fact, social capital is an essential capital for personal development as well as professional development of new graduates. This paper applies Fuzzy Analytical Hierarchy Process based on Geometric Mean Methodology to evaluate factors for measuring the social capital of graduates at Ho Chi Minh City Open University in Vietnam. The research results highlight the important role of social networks for graduates, in which a linking network is the most important, a bonding network is the second most important, and a bridging network is the third most important. In addition, the research shows that trust plays an even more important role than networks; and specific belief is more important than general belief.
\end{abstract}

Keywords-Education; human resource; fuzzy analytic hierarchy process, geometric mean; social capital network

\section{INTRODUCTION}

According to the Ministry of Labor, Invalids and Social Affairs, by the end of 2017, about 215,000 Vietnamese people with university degrees were unemployed. The situation shows that after graduation a certain percentage of students cannot find a job. This situation creates a tremendous waste of social resources and thus is an important issue to address. Various researchers have proposed solutions in terms of human capital development, and in particular focused on enhancing students' soft skills. The aim in this approach is to improve the likelihood of success in their job search process and to also obtain a higher starting salary. However, this is just one of the factors contributing to such success.

In the last few decades, interest and attention about social capital from scholars and researchers in various fields have been growing. In 1916, Hanifan, an American educator, introduced the concept of social capital. According to him, social capital refers to goodwill, friendship, sympathy, and social interaction between individuals and families [1]. More recent research all conclude that social capital should be regarded as the fourth necessary capital for individuals and communities, which is in addition to other traditional capital such as natural capital, physical capital and human capital. Therefore, it is necessary to develop an index to measure the social capital of students at Ho Chi Minh City Open University. Such research constitutes the foundation for future micro-research on the impacts of social capital in order to develop a strategy to maximize students' social capital. This paper presents different types of social capital as well as the development of a model to measure social capital of graduates from Ho Chi Minh City Open University.

\section{LITERATURE REVIEW}

According to Hanifan [1], social capital refers to goodwill, friendship, sympathy, and social interaction between individuals and families. When an individual meets a neighbor, this interaction will acquire social capital to meet various social needs and potentially improve the life standards of the community. Bourdieu [2] expands the concept of social capital by holding that all known networks contribute to the creation of social capital. This point is further clarified by Leonard and Onyx [3] as he points out that social capital is formed and developed by the participation of individuals in organizations and groups of people with the same interest. This is the structural angle of social capital. Paldam [4] approaches social capital from three categories of characteristics: trust, cooperation, and networking. In fact, trust is the foundation for standard behaviors, collaboration and networking, enabling members to act more effectively to pursue common goals.

According to social capital is a person's ability to work voluntarily with others and the pre-condition for this is social standards. Standards are understood as behavioral attitudes shared by most of individuals or groups in the society that are 
reinforced by sanctions. Such a standard may be a philosophy, religious doctrine or professional standards, or rules of conduct [5]. In addition, for everyone to act in accordance with a standard, trust is required as a condition.

Trust is defined as the willingness of a person to accept other people's actions based on the expectation that the other person will perform an action that is important without supervision or control. [6]. In other words, trust is the belief in others [7]. Trust is a core condition for standard behaviors, which is the source of cooperation. This is an important component in the formation of social capital. Thus, it could be said that social capital is a multidimensional, multidisciplinary concept and, subject to the purpose, approach and investigational method, and researchers can determine the inherent contents of social capital differently.

The concept of social capital is classified by three functions: bonding, bridging and linking [8, 9]. Bonding social capital refers to the trust and relationships within a group, such as among family members, relatives, and close friends $[10,11]$. The definition of bonding social capital shows that individuals may be closely bound to and "strongly" believe in other members in the network. From a structural component, this is a strong, close, and unofficially organized network.

Bridging social capital refers to the trust and network of inter-group relationships and networks among different communities. This type of social capital is beneficial in connecting external resources and helping to spread information. This view emphasizes the importance of loose relationships and general trust $[9,12]$. This network is often open and formally organized, typically in the form of a voluntary association or group. It is identified as including: (1) community networks, such as groups, associations (charities, clubs, skill clubs, physical training and sport teams, etc.) in the community, and (2) other social organizations and networks.

Linking social capital has the characteristic of having only one vertical link $[13,14]$. It refers to inter-class relationships, typically hierarchical relationships and trust in the institution, State, Party, Youth Union, Student Union, etc. Accordingly, this type of social capital is the key leverage to spread resources, concepts, and information among official organizations in the community. This is a very important factor in economic development.

From a cognitive perspective, trust is the basis of normative behavior and interrelationships. It is the source of all cooperation efforts aimed at achieving common goals [15]. Harpham [16] assumed that trust can be classified into two types, corresponding to the functions of bonding, bridging, and linking social capital, including: (1) specific trust: the belief in familiar persons in the closed network (bonding); and (2) generalized trust: the belief is open to strangers (close relationship), organizations and institutions (bridging, linking).

Many organizations and researchers have tried to model a social capital measurement index. Putnam [8] proposes the simplest method to measure social capital, which is the foundation for subsequent studies on social capital. The author analyzed institutional efficiency between northern and southern regions of Italy, which reflects structural components of social capital and did this by looking at participation in voluntary organizations to help explain much of the difference in institutional efficiency. The author also added a trust factor to his social capital measurement model.

Xue [17] has developed a social capital indicator based on a review of micro- and medium-scale social networks (relatives, friends, associations) and contents of the network (size, quality) in his study to explore the role of social networks in terms of the probability of finding a new job for new immigrants in Canada. The author applied regressive models as a fixed-effects logit model, random-effects logit model, and unobserved heterogeneity. Results of the research showed that social capital has a positive impact on the employment of migrant workers in the first four years.

Kanas [18]'s research on immigrants in Germany shows that social capital has a positive impact on immigrants' professional status and income. In this study, the author used a set of table data collected from socio-economic surveys in Germany (1984-2004). Subjects of the study were foreigners working in Germany ranging in age from 20 to 60 . The Heckman model was applied to control variables such as human capital, health, and social capital. Bonding and bridging social capitals were considered in the study by measuring relationship networks, volunteering activities, and migrant employment in relation to the original population. The results of the study confirm that various types of social interactions have a positive impact on the economic performance of immigrants. Migrant workers that are members of a group tend to achieve higher professional status than those that do not join a group. In particular, bridging social capital helps migrant workers develop opportunities to achieve a higher professional status, although this did not necessarily increase their income. In this study, the author did not measure social capital in terms of trust.

Mahuteau, et al. [10] uses data on migrant workers in Australia from household and labor income surveys in Australia during the 2002-2010 period. A social network index is constructed by means of principal component analysis (PCA). Social capital is measured by the following factors: (1) network participation, (2) interaction frequency, and (3) mutual contact and trust. A logit regression method was applied to answer the question, "Does social capital increase the probability of finding a job and increasing the income for immigrants?" Results of the study provide empirical evidence that the socio-economic environment has a positive impact on the probability of finding a job and increasing income for migrants, especially for women. In addition, it also shows that there is a significant difference in socio-economic status of migrant workers from different communities. For example, when the social capital index is increased by one unit while other factors remain unchanged, the odds ratio for employment was $32 \%$ for workers in general, $28 \%$ for migrant workers from English-speaking communities, and 17\% for migrant workers from non-English speaking communities. Further classifying persons into white-collar workers (skilled workers) and blue-collar workers, shows that social capital has 
a statistically significant impact on increasing the probability of finding employment for white-collar migrants [19].

\section{RESEARCH METHOdOLOGY AND RESUltS}

In the early 1970 s and in various publications in 1980, Thomas L. Saaty, an American mathematician, introduced a multi-standard decision-making method referred to as the analytic hierarchy process (AHP) [20-22]. This is a theoretically quantitative method that assists individuals or groups in evaluating, analyzing, and making decisions on complex multi-standard issues. The goal of this method is to quantify the relationships among various priorities in a given set of options by using a rating scale based on opinions and comments [23-26]. In particular, it emphasizes the importance of the evaluator's intuitive judgments as well as consistency in comparing the factors. AHP allows an expert to apply their knowledge and combine this with objective and subjective data in a logical hierarchy [27-30]. In addition, AHP combines both components of human thinking: qualitative and quantitative. The qualitative component is expressed by hierarchical arrangement while the quantitative component is expressed by description and evaluation. Preference is expressed by figures that can be used to describe perceptions of all intangible and tangible matters. It can be used to describe a person's emotions, intuition, and evaluation.

In recent years, many socio-economic scientists have utilized approaches based on set theory, especially fuzzy set theory. When Zadeh (1965) introduced the concept of fuzzy set, it was widely applied in a variety of disciplines, especially in the fields of engineering, and for computers and medicine. However, the application of fuzzy set theory in social and economic science is very limited.

Geometric Mean Method (GMM) is constructed solely based on fuzzy set theory and was introduced by Professor Zadeh (1965). He introduced fuzzy set theory to deal with uncertainty due to inaccuracy, unclearness, and ambiguity. For example, we cannot use any mathematical formula or explanation to express a saying, such as "He is a tall man." For example, the "high" characteristic here in Vietnam may be $1.7 \mathrm{~m}$ for many people, but others may have another number in mind $[24,31]$. Science has proven that fuzzy set theory is quite effective in dealing with problems without sharp boundaries and exact numbers. Moreover, fuzzy numbers are not the same as rigid words and mathematical equations, and instead it is very close to the natural language of humans [3234].

The following section manifests the computational process of the weights of the social capital indicators [34-39]:

Step 1. According to the experts about the relative importance of social capital indicators, the pairwise comparison matrices can be obtained. We use the fuzzy numbers determined in Table 1.

Step 2. We calculated the elements of the synthetic pairwise comparison matrix by using the geometric mean method suggested by Buckley [23]:
TABLE I. LINGUISTIC SCALES FOR THE RELATIVE IMPORTANCE

\begin{tabular}{|r|r|r|}
\hline Fuzzy number & Linguistic & $\begin{array}{r}\text { The scale of } \\
\text { the fuzzy number }\end{array}$ \\
\hline 1 & Equal & $(1,1,1)$ \\
\hline 2 & Weak Advantage & $(1,2,3)$ \\
\hline 3 & Not bad & $(2,3,4)$ \\
\hline 4 & Preferable & $(3,4,5)$ \\
\hline 5 & Good & $(4,5,6)$ \\
\hline 6 & Fairly good & $(5,6,7)$ \\
\hline 7 & Very good & $(7,8,9)$ \\
\hline 8 & Absolute & $(8,9,10)$ \\
\hline 9 & Perfect & \\
\hline
\end{tabular}

$\tilde{a}_{i j}=\left(\tilde{a}_{i j}^{1} \otimes \tilde{a}_{i j}^{2} \otimes \tilde{a}_{i j}^{3} \otimes \ldots \otimes \tilde{a}_{i j}^{n}\right)$

where $\tilde{a}_{i j}$ is the fuzzy comparison value of criterion $i$ to criterion $j$.

Step 3. To calculate the fuzzy weights of social capital indicators, we need to calculate $[40,41]$ :

$\tilde{r}_{i}=\left(\tilde{a}_{i 1} \otimes \tilde{a}_{i 2} \otimes \tilde{a}_{i 3} \otimes \ldots \otimes \tilde{a}_{i n}\right)^{1 / n}$

Moreover, for the weight of each criterion:

$\tilde{w}_{i}=\tilde{r}_{i} \otimes\left(\tilde{r}_{1} \oplus \tilde{r}_{2} \oplus \tilde{r}_{3} \ldots \oplus \tilde{r}_{n}\right)^{-1}$

where $\tilde{w}_{i}$ is the geometric mean of the fuzzy comparison of the $i^{\text {th }}$ criterion, which is indicated by a triangle fuzzy number $\tilde{w}_{i}=\left(L w_{i}, M w_{i}, U w_{i}\right)$.

Step 4. The The fuzzy weights are defuzzified by any defuzzification method. In this paper, we applied the following CoA method [42]:

$$
B N P_{w_{i}}=\left[\left(U_{w_{i}}-L_{w_{i}}\right)+\left(M_{w_{i}}-L_{w_{i}}\right)\right] / 3+L_{w_{i}}
$$

where $B N P_{w_{i}}$ is the Best Nonfuzzy Performance (BNP) value of the fuzzy weights of the $i^{\text {th }}$ criterion.

\section{RESUlTS AND DISCUSSION}

Ho Chi Minh City Open University was incorporated in 1990 and is the first open-model university in Vietnam. Over the last 26 years since establishment and subsequent development, the university has built up a system of facilities and affiliates throughout southern Vietnam, from Quang Ngai to $\mathrm{Ca} \mathrm{Mau}$, and in the Central Highland provinces and coastal regions and islands such as Con Dao, Phu Quoc. With a policy of socializing education to create learning opportunities for all people with many levels of education, the university has developed many forms of educational curriculums with flexible and convenient methods for learners, with subjects ranging from business administration to science and technology and for social sciences and the humanities. 
To help learners find the right jobs and be able to work after graduation, the university has developed a quality training curriculum. Additionally, the university has organized a variety of activities for students to participate in, such as activity groups, clubs, cultural events, entertainment, professional development activities, academic clubs, skills clubs, sports events, and extra-curricular activities such as Green Sunday, Saturday for Volunteer Work, student assistants, blood donation, green summer, volunteer spring, etc. Additionally, there are activities within various organizations, groups, and communities, such as the Communist Party of Vietnam, Youth Union, Student Union, etc. The annual rate of full-time students graduating from Open University is increasing in comparison with the number of enrolled students, from $46.68 \%$ in 2012 up to $70.75 \%$ in 2014 and $91 \%$ in 2015. In addition, about $90 \%$ of students gained employment after one year of graduation and about $67 \%$ of graduates have obtained work that suits their majors, and about $66 \%$ of students were employed immediately after graduation during the 5-year period of 2011-2015.

In the social capital index, the results of our study show that two components, network and trust, of graduates at Ho Chi Minh City Open University, have almost equal weights of 0.4095 and 0.5905 , respectively. This shows that both components, network and trust, play a very important role in the allocation of social capital. This result is consistent with the theoretical foundation of social capital [43].

Considering the network component only, a linking network is the most important type of network with a weight of 0.495 compared to 0.346 for a bonding network and 0.172 for a bridging network. Indeed, in traditional Asian cultures such as of the Vietnamese, the bonds among family members, relatives, and friends are very tight. People are willing to share and help each other, such as by providing food, accommodation, and economic support for children when they attend colleges. In addition, the role of the network is reflected in organizations and community groups such as the Party, Youth Union, and Student Union at Ho Chi Minh City Open University. In fact, Ho Chi Minh City Open University frequently organizes many extracurricular activities, social work, field trips, etc., to create an active environment for students to interact with others, to learn, and improve their life skills as well as soft skills before graduation. By participating in such activities, especially Delegation activities, students can gain countless benefits, and establish a strong foundation for their development in the future. It is important to meet and have exchanges with alumni students to have opportunities to improve their understanding and life experience. Additionally, network opportunities provide experiences to develop skills in communication, social interaction, organization of personal work, and in organizing events for the university, unions, associations, etc. Finally, regarding the trust component, specific trust is more important than general trust. This means that individuals in the network are more likely to engage in mutual trust because of their willingness to help and support each other.

\section{CONCLUSION}

This research developed a social capital index for graduates of Ho Chi Minh City Open University that consists of two components: network and trust. In particular, the network component includes bonding, bridging, and linking networks. The trust component consists of general trust and specific trust. The application of Fuzzy Analytical Hierarchy Process based on Geometric Mean Method shows the important roles of networks, where a linking network is the most important, followed by a bonding network, and bridging network. Additionally, trust plays a more important role than networks; and specific belief is more important than general belief. Importantly, social capital is a multidimensional, multidisciplinary concept and, subject to the purpose, approach and investigational method, where researchers determine the inherent contents of social capital differently. Future researchers can apply the findings from this study to explore the role of social capital in various areas such as the role of social capital in graduate job searches, how to improve student income and satisfaction level at the workplace after graduation, etc. In addition, further research may aim to provide solutions to enhance the social and behavioral satisfaction of students after graduation.

\section{ACKNOWLEDGMENT}

The authors gratefully acknowledge Ho Chi Minh City Open University (HCMCOU), 97 Vo Van Tan Street, Ward 6, District 3, Ho Chi Minh City, 72407, Vietnam for their supporting this research.

\section{REFERENCES}

[1] L. J. Hanifan, "The rural school community center," The Annals of the American Academy of Political and Social Science, vol. 67, no. 1, pp. 130-138, 1916.

[2] P. Bourdieu, "The forms of capital," Cultural theory: An anthology, pp. 81-93, 2011.

[3] R. Leonard and J. Onyx, "Networking through loose and strong ties: An Australian qualitative study," Voluntas: International Journal of Voluntary and Nonprofit Organizations, vol. 14, no. 2, pp. 189-203, 2003.

[4] M. Paldam, "Social capital: one or many? Definition and measurement," Journal of Economic Surveys, vol. 14, no. 5, pp. 629-653, 2000.

[5] F. Fukuyama, Trust: The social virtues and the creation of prosperity (no. D10 301 c. 1/c. 2). JSTOR, 1995.

[6] R. C. Mayer, J. H. Davis, and F. D. Schoorman, "An Integrative Model of Organizational Trust," Academy of management review, vol. 20, no. 3, pp. 709-734, 1995.

[7] J. F. Helliwell and R. D. Putnam, "Economic Growth and Social Capital in Italy," Eastern economic journal, vol. 21, no. 3, pp. 295-307, 1995.

[8] R. D. Putnam, "Bowling alone: America's declining social capital," in Culture and politics: Springer, 2000, pp. 223-234.

[9] C. L. Casey, "Linking Social Capital and Indirect Policy Tools: Fostering Equitable Community Reinvestment Responses?," Journal of Planning Education and Research, vol. 28, no. 4, pp. 413-425, 2009.

[10] S. Mahuteau, M. Piracha, M. Tani, and M. V. Lucero, "Immigration policy and entrepreneurship," International Migration, vol. 52, no. 2, pp. 53-65, 2014.

[11] B. Lancee, Immigrant performance in the labour market: Bonding and bridging social capital. Amsterdam University Press, 2012.

[12] M. S. Granovetter, "The Strength of Weak Ties," American journal of sociology, pp. 1360-1380, 1973. 
[13] W. Poortinga, "Social relations or social capital? Individual and community health effects of bonding social capital," Social Science \& Medicine, vol. 63, no. 1, pp. 255-270, 2006.

[14] S. Szreter and M. Woolcock, "Health by association? Social capital, social theory, and the political economy of public health," International Journal of Epidemiology, vol. 33, no. 4, pp. 650-667, 2004.

[15] P. Dasgupta, "Trust and cooperation among economic agents," Philosophical Transactions of the Royal Society B: Biological Sciences, vol. 364, no. 1533, pp. 3301-3309, 2009.

[16] T. Harpham, "The measurement of community social capital through surveys," in Social capital and health: Springer, 2008, pp. 51-62.

[17] L. Xue, "Social capital and employment entry of recent immigrants to Canada," Research and evaluation paper). Ottawa: Citizen and Immigration Canada, 2008.

[18] A. M. Kanas, The economic performance of immigrants: the role of human and social capital. Utrecht University, 2011.

[19] P. B. Sørenson, "Public finance solutions to the European unemployment problem?," Economic Policy, vol. 12, no. 25, pp. 222264, 1997.

[20] A. Daghouri, K. Mansouri, and M. Qbadou, "Information system evaluation based on multi-criteria decision making: A comparison of two sectors," International Journal of Advanced Computer Science and Applications, vol. 9, no. 6, pp. 291-297, 2018.

[21] M. B. Alqaderi, W. Emar, and O. A. Saraereh, "Concentrated solar power site suitability using GIS-MCDM technique taken UAE as a case study," International Journal of Advanced Computer Science and Applications, vol. 9, no. 4, pp. 261-268, 2018.

[22] S. Ahriz, A. El Yamami, K. Mansouri, and M. Qbadou, "Cobit 5-based approach for IT project portfolio management: Application to a Moroccan university," International Journal of Advanced Computer Science and Applications, vol. 9, no. 4, pp. 88-95, 2018.

[23] M. A. Marhraoui and A. El Manouar, "An AHP Model towards an Agile Enterprise," International Journal of Advanced Computer Science and Applications, vol. 8, no. 11, pp. 151-156, Nov 2017.

[24] S. K. Sehra, Y. S. Brar, and N. Kaur, "Applications of Multi-criteria Decision Making in Software Engineering," International Journal of Advanced Computer Science and Applications, vol. 7, no. 7, pp. 472477, Jul 2016.

[25] A. El Yamami, S. Ahriz, K. Mansouri, M. Qbadou, and E. Illoussamen, "Developing an Assessment Tool of ITIL Implementation in Small Scale Environments," International Journal of Advanced Computer Science and Applications, vol. 8, no. 9, pp. 183-190, Sep 2017.

[26] A. A. Malik, T. M. R. Khan, and A. Mahboob, "Evaluation of OLSR Protocol Implementations using Analytical Hierarchical Process (AHP)," International Journal of Advanced Computer Science and Applications, vol. 7, no. 11, pp. 338-344, Nov 2016.

[27] H. Setiawan, J. E. Istiyanto, R. Wardoyo, and P. Santoso, "The Group Decision Support System to Evaluate the ICT Project Performance Using the Hybrid Method of AHP, TOPSIS and Copeland Score," International Journal of Advanced Computer Science and Applications, vol. 7, no. 4, pp. 334-341, Apr 2016.

[28] A. R. Asghar, A. Tabassum, S. N. Bhatti, and S. A. A. Shah, "The Impact of Analytical Assessment of Requirements Prioritization Models: An Empirical Study," International Journal of Advanced Computer Science and Applications, vol. 8, no. 2, pp. 303-313, Feb 2017.

[29] A. I. El-Dsouky, H. A. Ali, and R. S. Rashed, "Ranking Documents Based on the Semantic Relations Using Analytical Hierarchy Process,"
International Journal of Advanced Computer Science and Applications, vol. 7, no. 2, pp. 164-173, Feb 2016.

[30] Juhartini and M. Suyanto, "The Use of Programming Languages on the Final Project Report by Using Analytical Hierarchy Process (AHP) (Case Study on the Student of Information Management Amikom Mataram)," International Journal of Advanced Computer Science and Applications, vol. 6, no. 9, pp. 310-317, Sep 2015.

[31] D. U. Ozsahin et al., "Evaluating Cancer Treatment Alternatives using Fuzzy PROMETHEE Method," International Journal of Advanced Computer Science and Applications, vol. 8, no. 10, pp. 177-182, Oct 2017.

[32] D. U. Ozsahin, B. Uzun, M. S. Musa, and I. Ozsahin, "Evaluating X-Ray based Medical Imaging Devices with Fuzzy Preference Ranking Organization Method for Enrichment Evaluations," International Journal of Advanced Computer Science and Applications, vol. 9, no. 3, pp. 7-10, Mar 2018.

[33] S. Basaran and O. J. Aduradola, "A Multi-Criteria Decision Making to Rank Android based Mobile Applications for Mathematics," International Journal of Advanced Computer Science and Applications, vol. 9, no. 7, pp. 99-107, Jul 2018.

[34] K. Gulzar, J. Sang, A. A. Memon, M. Ramzan, X. F. Xia, and H. Xiang, "A Practical Approach for Evaluating and Prioritizing Situational Factors in Global Software Project Development," International Journal of Advanced Computer Science and Applications, vol. 9, no. 7, pp. 181190, Jul 2018.

[35] P. T. Nguyen, T. A. Nguyen, Q. L. H. T. T. Nguyen, V. D. B. Huynh, and K. D. Vo, "Ranking project success criteria in power engineering companies using fuzzy decision-making method," International Journal of Advanced and Applied Sciences, vol. 5, no. 8, pp. 91-94, 2018.

[36] N. L. H. T. T. Quyen, P. T. Nguyen, and V. D. B. Huynh, "Prioritization of social capital indicators using extent analysis method," International Journal of Advanced and Applied Sciences, vol. 4, no. 10, pp. 54-57, 2017.

[37] N. T. Phong and N. L. H. T. T. Quyen, "Application fuzzy multiattribute decision analysis method to prioritize project success criteria," AIP Conference Proceedings, vol. 1903, no. 1, p. 070011, 2017.

[38] K. Gulzar, J. Sang, A. A. Memon, M. Ramzan, X. Xia, and H. Xiang, "A practical approach for evaluating and prioritizing situational factors in global software project development," International Journal of Advanced Computer Science and Applications, vol. 9, no. 7, pp. 181190, 2018.

[39] A. A. A. Gad-Elrab, T. A. A. Alzohairy, and A. S. Alsharkawy, "Cluster-Based Context-Aware Routing Protocol for Mobile Environments," International Journal of Advanced Computer Science and Applications, vol. 6, no. 1, pp. 1-10, Jan 2015.

[40] J. J. Buckley, "Fuzzy hierarchical analysis," Fuzzy Sets and Systems, vol. 17, no. 3, pp. 233-247, 1985/12/01 1985.

[41] T.-Y. Hsieh, S.-T. Lu, and G.-H. Tzeng, "Fuzzy MCDM approach for planning and design tenders selection in public office buildings," International Journal of Project Management, vol. 22, no. 7, pp. 573$584,10 / / 2004$.

[42] K. Vahdat, N. J. Smith, and G. G. Amiri, "Fuzzy multicriteria for developing a risk management system in seismically prone areas," Socio-Economic Planning Sciences, vol. 48, no. 4, pp. 235-248, 2014.

[43] P.V. Nguyen, P. T. Nguyen, Q. L. H. T. T. Nguyen, and V. D. B. Huynh, "Calculating Weights of Social Capital Index Using Analytic Hierarchy Process," International Journal of Economics and Financial Issues, vol. 6, no. 3, 2016. 